\title{
Do Moudawana ao Código da Família: processos e conteúdos de uma reforma estratégica"
}

\author{
Rachida Afilal $^{* *}$
}

\begin{abstract}
Resumo
No decorrer dos últimos dez anos, o Marrocos conheceu uma reviravolta decisiva na questão da promoção dos direitos das mulheres. O estabelecimento do Código da Família constitui um avanço qualitativo inaugurando assim uma nova era, na qual a abordagem jurídica é amplamente dominante. Nesta investida, as questões de atualização do status jurídico das mulheres, da igualdade dos sexos e da igualdade de oportunidades assim como da cidadania plenamente exercida por todos os cidadãos encontram-se no âmago do compromisso pelo desenvolvimento sustentável do Marrocos do século XXI.
\end{abstract}

Palavras-chave: Direitos das Mulheres, Código da Família, Moudawana, Marrocos.

\footnotetext{
" Recebido para publicação em dezembro de 2007, aceito em abril de 2008 [Tradução: Silvana Ruffier Scarinci].

** Professora e pesquisadora em Ciências Sociais e presidente da associação Leadership Féminin pour l'Egalité. http://iea:um5s:ac.ma
}

cadernos pagu (30), janeiro-junho de 2008:121-135. 
Do Moudawana ao Código da Família

From Moudawana to the Family Code:

Processes and Substance of a Strategic Reform

\begin{abstract}
Over the last ten years, Moroccan society was testified a veritable change in the women's rights promotion area. The implementation of the Family Code is a large quality step which announces a new era in which juridical approaches are enormously dominant. With this step, questions like women's legal status, sex equality and equality of opportunities, as well as citizenship available for all, are at the center of the compromise of Moroccan society with sustainable development at the $21^{\text {th }}$ century.
\end{abstract}

Key Words: Women's Rights, Family Code, Moudawana. 
Rachida Afilal

\section{Introdução}

A aplicação do novo Código da Família em fevereiro de 2004 foi amplamente aplaudida pelos diferentes agentes políticos, econômicos e sociais (partidos políticos, organizações dos direitos do homem, associações de mulheres...). Este avanço em envergadura marca uma reviravolta decisiva para um Marrocos voltado ao futuro e decididamente engajado num processo de democratização e modernização irrevogáveis. O processo de reforma da Moudawana ${ }^{1}$ vem ilustrar essa longa caminhada da democracia que poderá constituir uma experiência extremamente instrutiva no plano pedagógico, tanto em termos dos direitos das mulheres quanto em termos de democratização da sociedade.

Fruto de um longo percurso, pontuado pelo combate furioso travado pelas associações femininas e dos direitos dos homens, o novo Código da Família marca a instauração de valores de igualdade, de eqüidade, de justiça e de solidariedade, valores transversais irrigando sua filosofia e seu espírito.

Contextualizado por uma abordagem "jurídica", três grandes princípios constituem sua estrutura: garantir os direitos das mulheres, preservar os direitos $e$ a dignidade do homem $e$ fazer prevalecer o interesse supremo da criança. A abordagem "família" sobre o eixo da solidariedade, a complementaridade e a busca da coesão é amplamente privilegiada. Essa abordagem consiste em tornar diferentes componentes desta instituição de base, atores ativos para sua consolidação, seu equilíbrio e sua permanência definitiva.

Desse modo, um novo momento crítico e novos desafios para a família foram iniciados. Esses desafios a dispõe no centro do desenvolvimento social e a colocam inegavelmente diante das responsabilidades históricas em face da aposta pelo desenvolvimento humano sustentável. A modernidade e a fixação

1 N.T: Código marroquino da família. 
Do Moudawana ao Código da Família

de um estado democrático de direito, respeitoso de todos seus cidadãos estão no centro desta aposta.

Todavia, em vista das provas a vencer, os desafios não são menores. Diversas questões relativas à sua aplicabilidade permanecem em instância jurídica e convidam à reflexão. Um trabalho e uma reflexão à longo prazo continuam indispensáveis para acompanhar o processo de aplicação do novo código:

- Quais são as perspectivas de aplicação das novas reformas sabendo-se que a estratégia para acompanhar a aplicação desta reforma anunciada em sua origem nem sempre veio à luz?

Essa questão, apesar de estratégica na atualidade, não deveria mascarar uma questão não menos importante, a de restabelecer e salvaguardar a memória:

- Como o processo de estabelecimento do novo Código da Família é apresentado? Quais são suas principais etapas? Quais foram as diferentes apostas $e$ falhas que asseguraram a passagem do Moudawana ao Código da Família?

$\mathrm{O}$ interesse colocado nessa questão já qualificada como anacrônica vem do fato de que, com os desafios para a aplicação do novo Código da Família, a memória do processo sofre o risco de se enfraquecer. No entanto, o processo em seu âmbito pedagógico propõe-se, mais do que nunca, a se inscrever numa busca de conservação da memória.

Por outro lado, é importante sublinhar que a implantação do novo Código da Família e sua aplicação permitiu insuflar uma dinâmica e uma sinergia social favoráveis à melhoria do status da mulher. Sua promulgação como instrumento de eqüidade, de direito e de justiça é a sua concretização. O esforço aplicado neste sentido é inegável, ao mesmo tempo em que o processo de apropriação continua longo e lento. 
Rachida Afilal

\section{História da reforma: história de uma mobilização}

Longe de se constituir como uma aquisição fácil, a reforma da Moudawana é objeto de um longo e tumultuado processo, evoluindo ao ritmo de um combate feroz, pontuado por claras conquistas, mas também por frustrações. Durante a segunda metade do século passado, homens e mulheres, onde quer que fosse, convergiram para registrar essa caminhada rumo aos direitos humanos, emblemáticos da caminhada em prol da democracia no Marrocos. A exemplo desse combate, as etapas se multiplicaram, sem, no entanto, se assemelharem. Durante esse combate, o objetivo da igualdade, da eqüidade e da justiça tornou-se minuciosamente preciso. A passagem da abordagem fundada sobre o princípio da igualdade, por muito tempo exaltada, para o princípio de igualdade enquadrada pela justiça marca uma mudança qualitativa de envergadura. Desse modo:

1. Desde 1958, a Moudawana considerava as mulheres como menores de idade. A hierarquia, marcando a instituição familiar, centrada no conceito da obediência ( الطاعة), regia a relação da esposa com seu esposo. De fato, as relações de dependência enquadravam as relações dos homens com as mulheres no cenário da instituição familiar.

2. As tentativas de reforma da Moudawana, introduzidas entre os anos 60 e 80, sofreram várias derrotas. O momento não era ainda propício para a reforma, em razão dos desafios contextuais previstos. Enquanto isso, o movimento das mulheres ganhava organização $e$ as reivindicações se cristalizavam em torno do código do estatuto pessoal. Diversas associações femininas nasceram por volta da segunda metade dos anos 80 , inaugurando uma era de mobilização plural, mais institucionalizada, mais sistemática e mais organizada.

3. O ano de 1993 viu a primeira revisão do estatuto pessoal qualificado como descritiva. A campanha com um milhão de assinaturas pela revisão da Moudawana, iniciada pela Union de l'Action Féminine (União da Ação Feminina), constituiu um traço 
Do Moudawana ao Código da Família

marcante dessa década e foi um forte impulso para esta primeira reforma. Ora, sem atingir o espírito e menos ainda a filosofia da Moudawana, essa reforma configurou-se como uma dessacralização por excelência. Algumas das revisões preconizadas tiveram o mérito de subtrair o caráter imutável e rígido da Moudawana e de colocar as associações femininas e os direitos do homem diante de uma nova colocação. As reivindicações por maior igualdade e eqüidade tornam-se mais precisas para assegurar a passagem da reivindicação à mobilização. Durante esta década, o movimento das mulheres e dos direitos humanos ganham envergadura e estrutura para anunciar as premissas da colocação em rede, concretizado nos esforços de coordenação, de acordos e de mudança.

4. O Plan d'Action National pour l'Intégration des Femmes dans le Développement (Plano de Ação Nacional para a Integração das Mulheres no Desenvolvimento - PANIF) marcou uma mudança decisiva na história dos direitos das mulheres no Marrocos. Elaborado em $1999^{2}$ em torno de quatro frentes prioritárias (educação, saúde, emprego e status jurídico), o PANIF teve o mérito de colocar em cena pública um debate na sociedade sobre o projeto societal a ser preconizado. Desde então, a questão dos direitos da mulher, outrora alojado nos setores universitários ou em associações, irriga a esfera pública. Uma dinâmica favorável a uma reforma de base foi instaurada: entretanto, a diabolização do PANIFED e a satanização das forças que a sustentam permaneceram como pontos de destaque dessa etapa.

5. O resultado desse processo se deu em 2003-2004, com o surgimento do novo Código da Família, marcando o fim de uma batalha e inaugurando o início de um outro combate, o de colocá-lo em prática. O debate que acompanhou o trabalho da comissão real para a revisão da Moudawana e as reações que surgiram paralelamente, especialmente o nascimento da igualdade, trouxeram à cena pública as questões de referenciais: o

2 Governo do substituto do Sr. A. Youssoufi. 
Rachida Afilal

referencial islâmico, o referencial universal dos direitos do homem e o referencial social.

\section{Quadro de recapitulação}

$\begin{array}{lllll}1958 & 60-80 & 1993 & 1999 & 2003\end{array}$

\begin{tabular}{|c|c|c|c|c|}
\hline $\begin{array}{l}\text { Menoridade } \\
\text { da Mulher } \\
\text { - Tutela } \\
\text { - Submissão } \\
\text { - Wisaya }\end{array}$ & $\begin{array}{l}\text { Fracasso das } \\
\text { tentativas de } \\
\text { reformas: } \\
\text { - Organização } \\
\text { dos movimentos } \\
\text { das mulheres e } \\
\text { dos direitos do } \\
\text { homem }\end{array}$ & $\begin{array}{l}\text { Primeira } \\
\text { reforma: } \\
\text { - Dessacralização } \\
\text { do código do } \\
\text { Estatuto Pessoal }\end{array}$ & $\begin{array}{l}\text { Plano de Ação } \\
\text { para a Integração } \\
\text { da Mulher no } \\
\text { Desenvolvimento } \\
\text { (PANIFED): } \\
\text { - Diabolização }\end{array}$ & $\begin{array}{l}\text { Código da } \\
\text { Família: } \\
\text { - Uma reforma } \\
\text { de base, mas } \\
\text { também } \\
\text { previsão de } \\
\text { desafios }\end{array}$ \\
\hline
\end{tabular}

\section{Homenagem à memória}

Manter-se fiel ao histórico da evolução dos direitos das mulheres é também e principalmente prestar homenagem aos homens e às mulheres, militantes convictos e imbuídos dos valores dos direitos do homem e da igualdade. Neste percurso, Akhawate Assafae ${ }^{3}$ foi pioneiro nos anos 40, introduzindo a Agenda Feminina em suas atividades. Um vislumbre de suas reivindicações já demonstra o espírito engajado e inovador que animou sua busca e seu método. As militantes políticas dos anos 70, apoiadas pelos ativistas dos direitos humanos e militantes dos direitos das mulheres, tomaram a dianteira para fazer da melhoria das condições das mulheres um cavalo de batalha. Nesse ímpeto, um trabalho de teorização, de conceituação e de argumentação, aos quais se engajaram os/as pesquisadores/as, mostrou-se indispensáveis e úteis para apoiar as reivindicações, colocar um foco sobre as disfunções $e$ as disparidades e re-enquadrar os debates sobre a condição das mulheres. As premissas para uma

3 Akhawate Assafae, publicação do partido da "choura" (N.T: Akhawate Assafae: movimento feminino democrata do Marrocos). 
Do Moudawana ao Código da Família

defesa serena e bem argumentada da necessidade da reforma vieram à luz para anunciar uma nova era, que passou da reivindicação à mobilização social. As mídias tiveram um papel fundamental como porta-voz das mulheres. Desse modo, diversos jornais e revistas surgiram, como Kalima, "8 de março", Nissa mina al maghrib, "Mulheres do Marrocos"... Desde os anos 85, as associações femininas ganham em envergadura, alimentando o tecido de associações e colocando a questão das mulheres no centro das reivindicações sociais. $\mathrm{O}$ cinema $^{4}$, em termos de sensibilização do grande público nesse grande canteiro de reformas, contribuiu para uma revisão das questões de discriminação, da violência em relação às mulheres e de abusos de acordo com as novas perspectivas.

\section{Defesa no plural: um objetivo único, o código do Estatuto Pessoal}

Diversas fases constituíram as etapas do processo de defesa e sustentação de 50 anos dos direitos das mulheres. As principais etapas podem ser resumidas como segue abaixo:

- A campanha de um milhão de assinaturas;

- Campanha pela ratificação da CEDAW, reforma do Código do Estatuto Pessoal de 1993, Plano de Ação para a Integração das Mulheres ao Desenvolvimento, segunda reforma do Código do Estatuto Pessoal;

- Campanha de luta contra a violência em relação às mulheres;

- Os tribunais de divórcio;

- Os centros de escuta e de orientação jurídica;

- A marcha contra a pobreza feminina;

- As reuniões;

- Os memorandos;

- As cartas abertas;

4 Femmes et femmes, Procès d'une femme, Saída, Les enfants de la plage perdue, Les yeux secs. 
Rachida Afilal

- Conferências de Imprensa;

-Etc.

Desde os anos 2000 as datas históricas decisivas colocaram um ritmo regular no processo de aplicação do Código da Família, indicativo de um novo projeto societal. Entre 2001 e 2003, uma sucessão desenfreada de eventos e de datas grava-se na memória do processo:

- 5 de março de 2001: Sua Majestade, o Rei, recebe uma delegação de mulheres;

- 16 de março de 2001: Constituição da rede: "Primavera da Igualdade";

- 20 de março de 2001: Memorando apresentado à Sua majestade sobre as reivindicações das mulheres;

- 26 de abril de 2001: Implantação da Comissão Real para a Reforma da Moudawana, dirigido pelo Senhor Driss Dahhak;

- Junho de 2001-2002: Início de uma grande campanha de defesa e de sensibilização seguido por uma estratégia de comunicação e aproximação;

- Janeiro de 2003: o Rei muda o Presidente da Comissão e designa o Senhor Mhammed Bousetta para sua direção;

- Janeiro-Agosto de 2003: campanha de mídia e política pontuada por esforços de lobying, de coordenação e de criação de redes;

- 12 de setembro de 2003: a comissão entrega seu relatório;

- 10 de outubro de 2003: Discurso real apresentando o Código da família;

- Desde então: uma batalha vencida, outras previstas.

\section{Uma reforma à imagem da mobilização social}

4.1: Ao nível de enquadramento: novos paradigmas investidos?

A filosofia e o espírito que enquadram o Código da Família testemunham a ruptura realizada tanto num nível da visão quanto de conceito. No nível da visão, é importante sublinhar que este fica marcado por: 
Do Moudawana ao Código da Família

- A rotação em direção a um novo paradigma emergente, o da modernidade, do Estado de direito, da cidadania plena e ativa e do reconhecimento dos direitos...;

- A promoção de valores de eqüidade, de solidariedade e de justiça como valores fundadores de uma sociedade igualitária;

- No nível da projeção no futuro por uma visão de antecipação;

- Determinação de um novo perfil do Marrocos, um Marrocos moderno, democrático e engajado no século XXI, o século da globalização.

\section{2: No nível conceitual}

A adoção de uma formulação moderna que lance mão de um referencial dos direitos humanos e do fikh. ${ }^{5}$ A linguagem é mais simples, mais compreensível e mais acessível;

- A dimensão ética valorizando a mulher está presente a

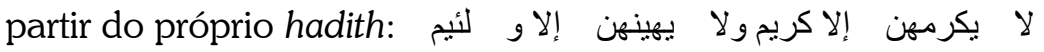

- A introdução dos direitos da criança e a consagração do princípio dos direitos supremos deste último;

- O respeito do princípio da reciprocidade dos deveres e direitos concretizados principalmente na co-responsabilidade dos dois cônjuges na gestão da família, na co-habitação legal baseada nas relações conjugais seladas com a justiça, a igualdade e a eqüidade;

- A implantação de medidas de acompanhamento que indiquem a vontade da operacionalização do Código da Família concretizada na instauração dos serviços especializados na legislação familiar, instalados no cerne dos tribunais de primeira instância;

- O ministério público é, a partir de então, parte ativa em todos os assuntos que instauram o Código da Família.

5 N.T: Jurisprudência islâmica. 
Rachida Afilal

\section{A previsão dos desafios}

No plano operacional, as diferentes avaliações que concernem à aplicação do Código da Família contemplam tanto os pontos fortes registrados, quanto os problemas observados. $\mathrm{O}$ balanço de aplicação é julgado de forma muito positiva pelo ministério de tutela e mitigado pelas associações femininas de direitos humanos. Certamente, a apropriação pelos diferentes interventores dos valores de igualdade e eqüidade irriga o Código da Família e é um trabalho de longo fôlego. Essa apropriação passa inelutavelmente por uma educação pelos direitos e pela igualdade, para garantir o respeito pelos princípios fundadores do código com foco nos direitos e na dignidade dos homens e das mulheres e no interesse supremo da criança. Sempre existem os riscos de infiltração do espírito da antiga Moudawana, que pairam sobre o novo código e colocam em perigo o equilíbrio e os avanços fragilizados por bolsões de resistência ainda vigorosos. Outro dos riscos é a ameaça de aplicação rápida demais decorrida da falta de homogeneidade do corpo de magistrados. Dentro desse quadro, a questão da funcionalidade e da autonomia das seções de família, que dependem do tribunal de primeira instância, permanecem problemáticas. Do mesmo modo, o poder dado aos juízes abre em demasia as portas para os abusos $e$ permite uma abordagem "personalizada" da aplicação do Código da Família.

Em relação à promulgação do Código da Família em 2004, os tribunais de família se estabeleceram e proliferaram através do Marrocos. Ora, por um lado, foram eles realmente dotados de meios humanos e logísticos lhes assegurando um funcionamento otimizado, sabendo-se que o sistema judiciário marroquino sofre de déficits tanto em termos de recursos humanos, quanto de administração? ${ }^{6}$

6 O Marrocos conta com: - Um número 3 vezes menor de magistrados que um país como a Tunísia; - Cerca de sessenta magistrados foram dispensados em 
Do Moudawana ao Código da Família

Por outro lado, se as marroquinas puderam ter sua representatividade, pela primeira vez, no âmago das seções de família, teriam elas se beneficiado por meios de ação e margem de manobras que lhes permitissem agir sem constrangimentos, sem linhas demarcatórias e sem pressões? A título indicativo, devemos assinalar que os estudos realizados sobre a organização da seção da família colocaram em destaque os problemas levantados da aplicação do novo código. Os conflitos de atribuições entre o Presidente do Tribunal de primeira instância e o Presidente da seção familiar, gerados por uma repartição de prerrogativas, nem sempre claras, sobretudo no domínio de procedimentos, criam uma série de obstáculos. A questão "quem comanda aqui?" é insistentemente colocada em relevo por esses estudos. Em alguns casos, as respostas trazidas à tona para essa questão tiveram repercussões freqüentemente dramáticas ${ }^{7}$ para as famílias.

De maneira evidente, revela-se que a ruptura com o espírito do antigo código não está completamente consumada, tanto pelos profissionais da justiça quanto por suas comunidades. ${ }^{8}$ As medidas prévias, ditas preparatórias ${ }^{9}$, para a colocação em vigor do Código da Família, não tiveram razões para resistência,

todos os tribunais de família no Marrocos desde 2004; - Ausência de assistentes sociais.

7 Ver estudo: mulheres, direitos da família e ordem judicial nos estados de Maghreb: Exemplo do Marrocos, Cadeira da UNESCO, "A mulher e seus direitos".

8 Ver estudo sobre: o estado de conhecimento das comunidades sobre os dispositivos do Código da Família, Projeto Liderança feminina, fevereiro de 2006, Rabat. 3. Guia prático sobre o novo Código, implantação das sedes destinadas a abrigar os foros de justiça da família, criação de uma seção de especialização em justiça da família no âmago do Instituto Superior de Magistratura, formação de profissionais de justiça, nominação de 161 juízes de família, promulgação de decretos de aplicação do código, elaboração do projeto do decreto relativo ao conselho da família, constituição de uma comissão de acompanhamento da aplicação do Código da Família, publicação de diversas decisões e projeto de decreto relacionado com a aplicação do novo Código da Família. 
entretanto, apresentam avanços visíveis. Exceto esses constrangimentos, a vontade de multiplicar os esforços e as iniciativas para derrubar para sempre o "castelo de cristal" são explicitamente expressas do começo ao fim.

Desde fevereiro de 2004, data da entrada em vigor do código, vastos canteiros de obras assim se abriram. As seções da família constituíram um destes canteiros. Além de sua função como protetor dos direitos dos componentes da família, os juízes asseguram desde então a mediação familiar, a resolução e a gestão de conflitos, missões de importância crucial nos procedimentos do divórcio judiciário, de sucessão e de proteção dos direitos das crianças. Por um lado, o tipo de abordagem da mediação, ditada pelo espírito do código se apóia no acompanhamento, na escuta, na investigação com vistas a expor informações confiáveis, a neutralidade, o senso de justiça e de eqüidade... Longe se ser um simples ato pontual, ela constitui um processo que se prova duradouro. Por outro lado, a dimensão social dessa missão impõe uma nova busca, consistindo em investigar as possibilidades de integração de novos profissionais capacitados que façam prevalecer as técnicas de comunicação, do acompanhamento, do relatório, da gestão de conflitos. Essa busca é a de profissionalizar diretamente a mediação, de dotá-la de rigor indispensável a seu desenvolvimento e fazer prevalecer seu aspecto preventivo. Que se trate da proteção dos direitos da criança, do divórcio ou ainda da sucessão, a mediação familiar pode se revelar como grande solução, assim como pode contribuir no nível da instituição familiar para reinstaurar o diálogo familiar ou reconstruir os laços familiares e restabelecer o lugar de trocas serenas nos conflitos. O casal é, assim, colocado em primeiro plano, uma vez que busca por si mesmo, através de um acompanhamento instrumentalizado, as soluções adequadas $e$ apropriadas. No nível da instituição judiciária, ela pode contribuir para aliviar os litigantes que aguardam por muito tempo os longos procedimentos do divórcio e da sobrecarga dos tribunais. 
Do Moudawana ao Código da Família

A título de lembrança, gostaríamos de assinalar que se formaram colegiados nas seções da justiça da família para estudar os assuntos relevantes da competência de tais seções. Com essa mesma intenção, os magistrados do Tribunal (homens e mulheres) e uma equipe de secretárias escrivãs juntaram-se para auxiliar os juízes na execução de suas missões. Estamos ainda longe de uma formação que favoreça a aplicação otimizada do novo Código da Família, no qual prevaleça seu espírito e seus valores fundadores. Implicitamente, o trabalho de acompanhamento, de orientação, de seqüência e de apoio dessas células aos magistrados e juízes terá por objetivo otimizar a ação judiciária de modo a i) assegurar a justiça e a eqüidade sociais nos prazos viáveis e ii) preservar o espírito de igualdade e solidariedade que fortalece o Código da Família.

\section{Conclusão}

O novo Código da Família constitui um projeto que provocou unanimidade entre diferentes interventores $e$ agentes sociais qualquer que fosse sua filiação. Mas longe de ser somente um conjunto de leis e de decisões, ele é, sobretudo, portador de uma filosofia e de um espírito permeado por valores de igualdade e de justiça. Não se trata somente de uma boa aplicação do novo código, mas da apropriação da cultura da igualdade pelos diferentes interventores e pelas comunidades envolvidas. Tal é o desafio a enfrentar. Em face desse desafio estratégico, novas provas apontam no horizonte, das quais se fará necessário principalmente:

- Colocar em prática uma aplicação com objetivos maiores;

- Uma estratégia nacional para enquadrar as reformas;

- Um mecanismo de direção institucional forte e estável;

- Colocar em prática uma aplicação fluida de outras reformas, como aquelas relacionadas ao código da nacionalidade ou da função pública; 
- Promoção da cultura de igualdade através de instituições educativas: escolas, mídia;

- Fazer do movimento das mulheres e da sociedade civil um fator de alargamento/reforço do processo de democratização em curso no Marrocos.

Enquanto isso, constatamos que o esforço de institucionalização e de jurisprudência em termos de direito da mulher e da família permanecerá insuficiente se, todavia, medidas de acompanhamento visando a habilitação e o reforço das capacidades dos interventores e dos objetivos não se desenvolvam. É desta habilitação que dependerá a aplicação adequada e fluida das novas disposições que não cessam de provocar, em alguns casos, resistências e formas de reticências visíveis e invisíveis. Uma boa apropriação, compreensão $e$ assimilação de novas disposições do Código da Família por diferentes categorias sociais passam, necessariamente, por uma estratégia de comunicação, de habilitação, de nivelamento estruturado, sistemático e permanente.

Certamente, o sucesso do novo Código da Família dependerá em grande parte de sua apropriação (ownership) pelos diferentes partidos envolvidos e agentes implicados (Ministérios envolvidos, governo, associações, comunidades de base...). Além disso, se os agentes institucionais (magistrados, juízes, advogados, agentes envolvidos...) supostamente atuam na fase anterior para sua boa aplicação, as comunidades de base devem, na fase posterior, assimilar bem seu conteúdo, espírito e filosofia. Para isso, esforços com o objetivo de habilitar profissionais da justiça $e$ a sensibilização $e$ a informação das comunidades foram permitidos. Um trabalho sobre a educação pela igualdade e pelos direitos deve ser consolidado, sabendo-se que a Moudawana se inscreve num projeto de sociedade enquadrado pela eqüidade social e igualdade. Essa orientação se confirmou certamente com a recente reforma do código da nacionalidade que vem dar ao conceito da cidadania plena e total uma dimensão de direito e de justiça. 